\title{
A história africana nas escolas brasileiras. Entre o prescrito e o vivido, da legislação educacional aos olhares dos especialistas (1995-2006) ${ }^{1}$
}

Anderson Ribeiro OLIVA ${ }^{\circ}$

Resumo: O presente artigo possui como intenção principal estabelecer um diálogo entre a legislação brasileira acerca do ensino da história africana e as leituras e opiniões formuladas por alguns africanistas sobre a temática. Sendo assim, buscamos na primeira parte do texto mapear a presença dos estudos africanos nos Parâmetros Curriculares Nacionais, na Lei 10639/03 e nas diretrizes formuladas para permitir sua implementação. Na segunda parte de nosso exercício a perspectiva foi a de observar como historiadores, antropólogos e demais especialistas analisaram a abordagem da história africana em nossos bancos escolares nos últimos dez anos. O resultado do diálogo revela que, apesar das indicações encontradas em parte da legislação educacional brasileira, uma longa lacuna se apresenta quando o assunto a ser tratado nas salas de aula envolve temas africanos.

Palavras-chave: Ensino da história africana; Lei 10639/03; História da África.

Transcorridos quase cinco anos da promulgação da Lei Federal 10639/03, seria legítimo se perguntássemos sobre as trilhas seguidas por nossos pesquisadores e educadores na construção de reflexões e propostas para o ensino da história africana nas escolas brasileiras. Não parece ser novidade que às escassas experiências escolares sobre a temática, identificadas antes desse período, somou-se um conjunto multifacetado e extenso de tentativas de aplicar ou permitir o cumprimento dos textos legais formulados sobre o assunto. Assim, cursos de

- Professor Doutor de História da África - Instituto de Ciências Humanas - IH - Universidade de Brasília - UNB - 70910-900 - Brasília DF - Brasil. E-mail: oliva@unb.br

HISTÓRIA, São Paulo, 28 (2): 2009 
especialização, extensão, formação de professores, seminários, congressos e publicações, vêm tentando contemplar os mais diversos objetos ligados à abordagem em sala de aula das trajetórias e características históricas africanas.

No entanto, a resposta ao questionamento acima lançado que envolve um significativo esforço de mapeamento e busca das propostas, que desde então podem ser encontradas em profusão - não deve ocorrer sem outra reflexão, talvez de caráter seminal para todos os esforços que ocorrem em torno do tema. É fundamental um entendimento mais pontual sobre a legislação existente acerca do citado objeto e da opinião de alguns de nossos africanistas sobre o ensino da história africana. Se, as atividades marcadas pela excelência de seus executores e de seus conteúdos proliferam, outras, têm se demonstrado deficientes em suas intenções e encaminhamentos.

Dessa forma, a intenção do presente artigo é realizar uma leitura pontual sobre os principais textos legais que procuraram balizar a abordagem escolar dos estudos africanos em âmbito nacional, vigentes desde a década de 1990 - a Lei de Diretrizes e Bases da Educação (LDB), os Parâmetros Curriculares Nacionais (PCNs), a Lei 10.639/03 e as Diretrizes Curriculares Nacionais para a Educação das Relações Étnico-Raciais e para o Ensino de História e Cultura Afro-Brasileira e Africana -, assim como dialogar com alguns dos principais especialistas em estudos africanos que buscaram, de forma sistematizada ou não, opinar sobre o tema.

\section{O que dizem os textos oficiais. Nas trilhas do prescrito}

Se a presença da História da África nos Currículos e nos livros escolares brasileiros, até meados dos anos 1990, pode ser considerada insignificante, já que o continente africano aparecia sempre retratado de forma secundária, associado ao périplo marítimo dos séculos XV e XVI, ao tráfico de escravos e aos processos históricos do Imperialismo, Colonialismo e das Independências na África, esse quadro passou a sofrer uma 
A HISTÓRIA AFRICANA NAS ESCOLAS BRASILEIRAS...

evidente modificação a partir de 1996. A entrada em vigor da nova Lei de Diretrizes e Bases da Educação (LDB), de 1996 (lei 9394/1996), seguida pelos Parâmetros Curriculares Nacionais (PCNs), da área de História, em 1998, sinalizavam para uma possível, mesmo que frágil, aproximação com os estudos africanos. Em um claro reflexo desses sinais podemos encontrar, a partir de 1999, livros didáticos de História, utilizados entre a $5^{a}$ e $8^{\mathrm{a}}$ série do Ensino Fundamental, que incluíam em seus volumes pelo menos um (1) capítulo sobre a história africana, quase sempre vinculada ao período que se estende do século VII ao XVIII. ${ }^{2}$ Antes daquele ano não localizamos nenhuma coleção de livros didáticos com essa característica.

Talvez, como um potencializador desse processo - apesar de seus efeitos estarem ainda sob avaliação e os resultados obtidos precisarem de uma mensuração mais detalhada -, em janeiro de 2003, foi promulgada a Lei $n^{\circ} 10639$, que, alterando o texto da LDB, tornou obrigatório o ensino da história africana nas escolas brasileiras (os PCNs apenas sugeriam os conteúdos). Seguiu-se a essa lei, já em 2004, a formulação das Diretrizes Curriculares Nacionais para a Educação das Relações Étnico-Raciais e para o Ensino de História e Cultura AfroBrasileira e Africana. Todos esses documentos apontavam para a importância ou para a obrigatoriedade da introdução do estudo da história africana nas escolas brasileiras de Ensino Fundamental e Ensino Médio. ${ }^{3}$ Vejamos, portanto, o lugar reservado à África nos textos oficiais.

\section{Os estudos africanos na LDB e nos PCNs}

Segundo os PCNs um dos objetivos principais do Ensino Fundamental se apóiam na necessidade de que estudantes e professores devam reconhecer e valorizar a "pluralidade do patrimônio sociocultural brasileiro", e, ao mesmo tempo, conhecer também os "aspectos socioculturais de outros povos (...) posicionando-se contra qualquer discriminação". ${ }^{4}$ Neste caso, a própria LDB, já determinava que a abordagem da história 
do Brasil nas escolas deveria "levar em conta as contribuições das diferentes culturas e etnias para a formação do povo brasileiro," entendidas nos termos empregados pela lei como as "matrizes indígena, africana e européia". ${ }^{5}$ Esses elementos foram sintetizados em um dos pressupostos centrais para 0 ensino da História defendidos pelos PCNs.

Os Parâmetros Curriculares Nacionais para a área de História (...) destacam os compromissos e as atitudes de indivíduos, de grupos e de povos na construção e na reconstrução das sociedades, propondo estudos das questões locais, regionais, nacionais e mundiais, das diferenças e semelhanças entre culturas, das mudanças e permanências no modo de viver, de pensar, de fazer e das heranças legadas por gerações. ${ }^{6}$

Tal perspectiva parece ser contemplada também pelas indicações de que o estudo sobre as relações estabelecidas entre sociedades e grupos - localizados em dimensões temporais e espaciais sincrônicas ou diacrônicas - devam ser caracterizadas pelo respeito e reconhecimento das "semelhanças e diferenças, continuidades e descontinuidades, conflitos e contradições sociais". ${ }^{7}$ Talvez envolvendo esta iniciativa esteja um outro princípio: o do entendimento sobre a alteridade.

A percepção da alteridade está relacionada à distinção, de modo consciente, das diferenças, das lutas e dos conflitos internos aos grupos sociais ou presentes entre aqueles que vivem ou viveram em outro local, tempo ou sociedade. E está relacionada à construção de uma sensibilidade ou à consolidação de uma vontade de acolher a produção interna das diferenças e de moldar valores de respeito por elas. ${ }^{8}$

Para além desses elementos, não subtraindo a propriedade das reflexões acerca das lacunas deixadas, e não nos afastando deles, nos concentremos nas leituras acerca da África, propostas pelos textos legais, já que o ensino da história africana aparece, mesmo que implicitamente, justificados por esses aspectos. 
A HISTÓRIA AFRICANA NAS ESCOLAS BRASILEIRAS...

Segundo determinação da própria LDB, os Parâmetros Curriculares ficariam caracterizados por um perfil mais sugestivo do que indicativo do que deveria materializar o processo de ensino e aprendizagem nas escolas. Sua estrutura principal, dividida em áreas de conhecimento e nos chamados temas transversais, procurava estabelecer um grande conjunto de assuntos a ser trabalhado nos vários níveis e ciclos da educação. ${ }^{9} \mathrm{O}$ estabelecimento pontual dos conteúdos tratados por cada série ficaria a cargo dos Currículos Estaduais e Municipais.

Da mesma forma, outro elemento que se destaca é a indicação explícita de que o documento se propõe a servir como um amplo referencial de abordagens, e não como um instrumento coercitivo/impositivo/excludente dos conteúdos a serem tratados. Mesmo assim, por ser o elemento de origem e de referência para os outros documentos oficiais correlatos sua importância não deve ser colocada em segundo plano. ${ }^{10}$

Apesar de se encontrarem cadenciados por um discurso defensor da flexibilidade em relação aos objetos a serem estudados e sinalizarem para a inclusão equilibrada dos recortes associados ao tratamento das histórias do Brasil, Europa, América e África, os PCNs, em vários trechos, ficam caracterizados por indicações de abordagens superficiais, pouco específicas e insuficientes sobre as temáticas e objetos que poderiam envolver o estudo da história africana. Apenas identificamos referenciais mais assertivos sobre assuntos possivelmente vinculados ao ensino fundamental no tópico destinado ao entendimento sobre o tema da "Pluralidade Cultural". Neste caso, não podemos deixar de notar o acerto do documento em apontar para possíveis recortes da história das sociedades africanas e para o cuidado em desvincular sua abordagem do estudo da história da escravidão e do tráfico.

O estudo histórico do continente africano compreende enorme complexidade de temas do período pré-colonial, como arqueologia; grupos humanos; civilizações antigas do Sudão, do sul e do norte da África; o Egito como processo de civilização 
africana a partir das migrações internas. Essa complexidade milenar é de extrema relevância como fator de informação e de formação voltada para a valorização dos descendentes daqueles povos. Significa resgatar a história mais ampla, na qual os processos de mercantilização da escravidão foram um momento que não pode ser amplificado a ponto que se perca a rica construção histórica da África. O conhecimento desse processo pode significar o dimensionamento correto do absurdo, do ponto de vista ético, da escravidão, de sua mercantilização e das repercussões que os povos africanos enfrentam por isso. ${ }^{11}$

No entanto, nesse mesmo tópico do documento, seus redatores evidenciam a grande dificuldade em definir, nominalmente, os possíveis conjuntos civilizatórios ou as sociedades africanas a serem abordados ou diretamente vinculados à história do Brasil, já que, para o texto oficial, os povos assim definidos seriam denominados de "daomeanos, iorubás, gegês, kêtus, bantos, congoleses, angolanos e moçambicanos". ${ }^{12}$ A confusão não é apenas de identificação dessas sociedades, mas também da sua própria distribuição temporal-contextual.

Fora esse enfoque, não iremos encontrar nas outras partes dos PCNs, inclusive na dedicada exclusivamente à História, nenhum recorte caracterizado por maior especificidade. Por exemplo, no que se refere ao estudo da História para o $3^{\circ}$ ciclo do Ensino Fundamental, ${ }^{13}$ ou seja, as $5^{\mathrm{a}}$ e $6^{\mathrm{a}}$ séries, os conteúdos, organizados a partir de um eixo temático central, "História das relações sociais, da cultura e do trabalho", e dos subtemas, "As relações sociais e a natureza" e "As relações de trabalho", e, correspondentes a uma temporalidade que se estende da origem da humanidade aos séculos XVI e XVII, pouca atenção dedicam ao continente africano. ${ }^{14}$ Encontramos aí algumas passagens, nas quais, a história da África é lembrada apenas de forma superficial e pouco consistente.

Uma primeira indicação objetiva de conteúdos ligados à temática aparece associada à questão das origens da humanidade e das primeiras civilizações humanas, assuntos 
A HISTÓRIA AFRICANA NAS ESCOLAS BRASILEIRAS...

quase sempre, mesmo que não de forma obrigatória, tratados na $5^{a}$ série. $^{15}$ Se no texto destinado a "Pluralidade Cultural" encontramos algumas referências sobre as temáticas ou alguns recortes envolvendo o estudo da história da África, nesta parte dos PCNs, observamos um movimento contrário, ou seja, a total ausência de sugestões sobre quais civilizações, os autores dos livros escolares, professores e alunos deveriam eleger para estudo - iniciativa, por exemplo, que ocorre no caso das sociedades indígenas americanas. Da mesma forma não são encontradas indicações acerca dos elementos conceituais que deveriam conduzir a abordagem do assunto. Sabemos, para ilustrar nosso argumento, que, a questão da "anterioridade das civilizações africanas" ${ }^{16}$ foi um dos grandes celeumas levantados por parte da historiografia africana. Sabemos também que, tal especificidade de enfoque, não poderia ser contemplada em um texto como este, mas as referências a alguns conjuntos civilizatórios africanos seria um bom encaminhamento a seguir.

Na seqüência dos conteúdos elencados para o terceiro ciclo do Ensino Fundamental, os PCNs dão um salto das primeiras civilizações para o processo de Expansão Marítima Européia dos séculos XV e XVI, ponto, no qual, ocorre novamente, a inserção da África como um tema secundário. ${ }^{17}$ Encerrando esse primeiro eixo temático, os Parâmetros Curriculares sugerem um importante recorte acerca de assuntos relacionados ao campo da percepção artística e da história cultural, ao indicar a necessidade de se estudar "(...) a natureza, o corpo, a sexualidade e os adornos dos povos africanos e europeus (...) e a natureza nas manifestações artísticas africanas e européias". Apesar de ignorar um importante aspecto ligado ao imaginário africano do início da era moderna, ou então, relacionado às representações européias elaboradas sobre os africanos no decorrer do medievo europeu, ao sinalizar para a abordagem da "natureza no imaginário europeu medieval e renascentista", ${ }^{18} \mathrm{o}$ texto aponta um fértil objeto a ser tratado nas salas de aula, mesmo sem perceber tal possibilidade.

Identificamos também uma clara contradição ou ambigüidade na indicação dos conteúdos a serem enfocados. No 
campo do discurso ou da teoria, o documento defende uma abordagem sem preferências de uma temática sobre outra, sendo apenas recomendado que "os conteúdos da História do Brasil, da América e do mundo" sejam "agrupados separadamente", com o intuito "de permitir a especificação de acontecimentos históricos pertinentes". ${ }^{19}$ No entanto, e apesar das idéias apresentadas, percebemos uma clara concentração dos temas voltados para o estudo da história do Brasil, da Europa e da América, ficando a África e o Oriente em um plano secundário. É o caso, por exemplo, do subtema, "as relações de trabalho". No entanto, a ênfase dos Parâmetros volta a recair sobre um antigo enfoque concedido aos africanos na história do Brasil: a escravidão.

(...) tráfico de escravos e mercantilismo; escravidão africana na agricultura de exportação, na mineração, produção de alimentos e nos espaços urbanos; lutas e resistências de escravos africanos e o processo de emancipação; trabalho livre no campo e na cidade após a abolição (...); comerciantes e mercadores de escravos; escravidão indígena e africana na América colonial $(\ldots .)^{20}$

Parece-nos certo a necessidade de dar vazão ao grande número de estudos inovadores tutelados pela história social da escravidão no Brasil nas últimas três décadas, mas a história da escravidão não se confunde com a História da África, e isso precisava ficar, de alguma forma, explícito no documento.

Porém, a história dos ofícios e das práticas de trabalho nas sociedades africanas não passa de todo despercebida, sendo que o destaque acaba por se estender das sociedades caçadoras e coletoras às atividades agrícolas, artesanais, sacerdotais, militares, administrativas, mercantis, realizadas ao longo das várias temporalidades. No entanto, ao abordar o universo do trabalho no continente em um extenso recorte temporal, é possível que os autores tenham negligenciado os diversos contextos e suas especificidades. Já acerca do enfoque das 
A HISTÓRIA AFRICANA NAS ESCOLAS BRASILEIRAS...

atividades profissionais contemporâneas a única referência feita é a do turismo.

(...) caçadores e coletores na África e na Europa em diferentes épocas; agricultores, sacerdotes, guerreiros e escribas na África e no Oriente; artífices, comerciantes e navegadores na África e no Oriente; escravidão antiga na África, no Oriente e na Europa; (...) agricultura, comércio, indústria, artesanato e serviços urbanos na África e Ásia; (...) natureza e economia do turismo na África. ${ }^{21}$

O texto oficial também chama a atenção para as diferentes formas de escravidão praticadas, inclusive naquele continente, ao indicar a necessidade de "(...) caracterizar e analisar diferentes tipos de escravidão, servidão e trabalho livre", o que permite que estudantes e docentes construam outras imagens dos africanos, contrárias àquelas figuras que os confundem com o exclusivo papel de vítimas da escravidão, alocando-os na função de protagonistas da história e não apenas como coadjuvantes. $^{22}$

Já para o quarto ciclo do Ensino Fundamental, $7^{\mathrm{a}}$ e $8^{\mathrm{a}}$ séries, o eixo temático proposto foi o da "História das representações e das relações de poder", que também se subdivide em dois subtemas, "Nações, povos, lutas, guerras e revoluções", e, "Cidadania e cultura no mundo contemporâneo". ${ }^{23}$ Neste caso, o recorte cronológico estende-se do século XVII ao dias atuais, com algumas nuances temáticas que levam as abordagens e incursões pelo mundo moderno e contemporâneo, ocidental e oriental. Assim como no resto dos PCNs, seus autores alertam que os conteúdos apresentados servem "apenas como sugestões de possibilidades, que não devem ser trabalhados na sua integridade". ${ }^{24}$

As primeiras referências à história africana aparecem no tópico os "Processos de constituição dos Estados Nacionais, confrontos, lutas, guerras e revoluções na Europa, na África e no Oriente", vinculados ao subtema "Nações, povos, lutas, guerras e revoluções" ${ }^{25}$. De forma muito semelhante ao terceiro ciclo, onde as inconsistências e imprecisões em relação aos estudos 
africanos são muito significativas, quando comparadas à atenção ou indicações de estudos para os outros conjuntos civilizatórios e continentes, os conteúdos sugeridos para o quarto ciclo revelam também inquietantes esquecimentos acerca da abordagem da história daquele continente.

Enquanto a África é apresentada apenas a partir das experiências históricas das chamadas "culturas tradicionais dos povos africanos", outros conjuntos civilizatórios têm suas contribuições localizadas em um recorte temático-cronológico muito mais amplo. É o caso, por exemplo, da abordagem enfocando alguns impérios da humanidade como o "Império Persa, Império Macedônio, Império Romano" ou ainda as "cidades-estado gregas, a República Romana e a descentralização política na Idade Média". ${ }^{26}$ Podemos encontrar para esses modelos, elementos similares ou convergentes na trajetória histórica das sociedades africanas, mas nenhum deles é lembrado. Não citá-los é um dado que revela o olhar eurocêntrico lançado sobre a história. Segundo a lógica indicada pelos PCNs, mesmo que o texto não explicite essa perspectiva, a África deve ser estudada a partir de suas sociedades tradicionais e não por suas formações estatais e civilizações. Outra abordagem sugerida é a que envolve seus espectros contemporâneos, assim selecionados:

(...) colonialismo e imperialismo na África, descolonização das nações africanas, Estados Nacionais africanos, experiências socialistas na África (Angola, Moçambique etc.); apartheid e África do Sul, fome e guerras civis na África, guerras entre as nações africanas, povos, culturas e nações africanas hoje. ${ }^{27}$

São temas, de fato, de extrema relevância. Mas é explícito que as indicações acima transcritas sinalizam para uma trilha envolvida pelas sombras da supervalorização dos temas ligados apenas aos problemas vivenciados pelo continente nos últimos anos, excluindo, é claro, a abordagem de assuntos clássicos como o colonialismo, o imperialismo e as independências africanas. Neste caso, o estudo das "culturas e nações africanas" 
A HISTÓRIA AFRICANA NAS ESCOLAS BRASILEIRAS...

se perde em um formato abstrato e disperso. Por exemplo, no subtema, "Cidadania e cultura no mundo contemporâneo", ${ }^{28}$ a única referência feita à África ocorre em relação aos movimentos migratórios dos africanos para a União Européia. Fica de fora uma quantidade significativa de possíveis abordagens positivas acerca das múltiplas realidades atuais relacionadas à história africana, como no campo da produção artística, do pensamento filosófico, da produção nas mais diversas áreas do conhecimento, na música, nas estéticas, entre outros possíveis tópicos.

Outro aspecto relevante da questão é de ordem estrutural/conceitual dos Parâmetros. Parece-nos certo que a justificativa para o estudo da história africana não se encontra no reconhecimento da autonomia e relevância histórica associadas ao continente pela historiografia produzida nas últimas décadas. O tema encontra-se vinculado a um dos aspectos que mais debates geraram sobre o documental oficial: o tratamento da chamada diversidade social e cultural brasileira. De acordo com a historiadora Rebeca Gontijo, na tentativa de refutar as influências das teses da "democracia racial" na escola, os PCNs, se concentram nos debates sobre a pluralidade e a diversidade culturais, e não mais na discussão sobre a miscigenação enfatizada anteriormente:

A posição dos PCNs, portanto é bastante clara no que diz respeito a reconhecer e valorizar os grupos minoritários que compõem o Brasil, recuperando suas contribuições e especificidades ("reconhecer" e "valorizar" as diferenças são palavras de ordem), posicionando-se contra a diluição da cultura - favorecida pelas idéias de miscigenação e pelo "mito da democracia racial" - e, ao mesmo tempo, afirmando a diversidade como "traço fundamental na construção de uma identidade nacional que se põe e repõe permanentemente $(\ldots)^{29}$

Não iremos entrar no mérito da polêmica, mas para alguns historiadores que se debruçaram acerca da questão, a nova 
perspectiva seria de alguma forma tributária das teorias do multiculturalismo, ${ }^{30}$ modelo que também seria inadequado para o entendimento das relações que teriam alicerçado a formação da sociedade brasileira. O certo é que, apesar de já incluir determinados temas voltados para o estudo da história africana, os PCNs pecam por origem, seja pela falta de uma perspectiva centrada na própria trajetória das sociedades em África, seja pela escolha de uma estrutura de conteúdos que defende a articulação da temática sempre articulada com a história do Brasil. Segundo essa lógica, valoriza-se mais a "África" que existiria dentro do Brasil - as contribuições africanas na formação da sociedade brasileira - do que a história do continente que nos divisa pela fronteira do Atlântico Sul.

\section{A Lei 10639/03 e seus desdobramentos: a busca por balizas para a abordagem da história da África nas escolas}

O quadro anteriormente descrito, marcado por um recorte superficial ou pouco indicativo sobre os conteúdos associados aos estudos africanos, tendeu a sofrer uma clara confrontação com a promulgação da Lei Federal 10639, de 9 de janeiro de 2003 (que alterou a lei 9394/1996), e, principalmente, com o posterior parecer do Conselho Nacional de Educação (CNE) (CNE/CP 032004, de 10.03.2004), transformado na resolução 1 , de 17 de junho de 2004. Esses documentos, frutos de uma série de inquietações e ações originadas dos movimentos negros organizados, dos interesses e apontamentos de pesquisadores e intelectuais, da análise de técnicos em educação e do comprometimento de alguns parlamentares, traçaram linhas mais claras, porém não menos insuficientes, sobre a questão. Apesar de apontarem de forma mais substanciada para possíveis temas e objetos a serem tratados nas salas de aula, e, conseqüente, nos manuais escolares, os textos citados dedicam pouca atenção à África, concentrando suas propostas mais nas questões relacionadas aos estudos da história e da cultura afrobrasileiras. 
A HISTÓRIA AFRICANA NAS ESCOLAS BRASILEIRAS...

A redação da Lei 10639/03 é sintética e direta - como de fato deveria ser - em relação as suas determinações - "O conteúdo programático a que se refere o caput deste artigo incluirá o estudo da História da África e dos Africanos (...)" (Lei Federal 10639/03) -, ficando a tarefa de especificar ou regulamentar a temática a cargo de outras instâncias, como o Conselho Nacional de Educação.

Transcorridos mais de um ano da promulgação da lei, ocorrida em março de 2003, o CNE, aprovou o parecer elaborado pela conselheira Petronilha Beatriz Gonçalves e Silva acerca das Diretrizes Curriculares Nacionais para a Educação das Relações Étnico-Raciais e para o Ensino de História e Cultura AfroBrasileira e Africana, transformado em Resolução em junho daquele mesmo ano. Posteriormente, em outubro de 2004, uma publicação conjunta entre o Ministério da Educação e a Secretaria Especial de Políticas de Promoção da Igualdade Racial (Seppir), acabou por normatizar e divulgar os elementos de regulamentação e aplicação da lei 10639/03. Vejamos o tratamento concedido à história africana nesse documento.

Um primeiro aspecto a destacar refere-se a um importante alerta realizado pelas Determinações das Diretrizes, no que nos pareceu ser um diálogo direto com as visões elaboradas por alguns intelectuais e teóricos africanos e afro-descendentes, associados ao movimento que o historiador guineense Carlos Lopes denominou como Corrente da Superioridade Africana. ${ }^{31}$ Grande parte das leituras daqueles intelectuais defendia a inversão do foco histórico de matriz eurocêntrica, para um foco conduzido por uma matriz afrocêntrica. ${ }^{32}$ Os redatores do documento, parecendo conhecer as críticas e especificidades desse postulado teórico, alertam para os cuidados e os caminhos que as diretrizes curriculares deveriam seguir nas escolas.

É importante destacar que não se trata de mudar um foco etnocêntrico marcadamente de raiz européia por um africano, mas de ampliar o foco dos currículos escolares para a diversidade cultural, racial, social e econômica brasileira. ${ }^{33}$ 
Dessa forma, como explícita a resolução, o "conhecimento e a valorização da história dos povos africanos" deveriam ocorrer em todos os níveis e modalidades do ensino brasileiro "como conteúdo de disciplinas, particularmente, Educação Artística, Literatura e História do Brasil, sem prejuízo das demais". ${ }^{34}$ Outro importante elemento a destacar refere-se a um aspecto até então inédito nos documentos analisados: a descrição pontual de objetos e temas que deveriam ser tratados na abordagem da história africana nas salas de aulas brasileiras. No caso específico da disciplina História, os autores apontam uma extensa lista de assuntos e recortes que passam por temáticas como a tradição oral e a ancestralidade, e recobrem uma larga seleção temporal e societária, se estendendo do Egito e da Núbia antigas até a África dos dias contemporâneos. Outra ênfase encontrada nas indicações de conteúdos é a tentativa de quebrar as tendências em ler as sociedades africanas apenas pelas faces negativas do continente ou pelo grande conjunto de estereótipos que recaem sobre elas.

Em História da África, tratada em perspectiva positiva, não só de denúncia da miséria e discriminações que atingem o continente, nos tópicos pertinentes se fará articuladamente com a história dos afrodescendentes no Brasil e serão abordados temas relativos: - ao papel dos anciãos e dos griots como guardiões da memória histórica; - à história da ancestralidade e religiosidade africana; - aos núbios e aos egípcios, como civilizações que contribuíram decisivamente para o desenvolvimento da humanidade; - às civilizações e organizações políticas précoloniais, como os reinos do Mali, do Congo e do Zimbabwe; - ao tráfico e à escravidão do ponto de vista dos escravizados; - ao papel de europeus, de asiáticos e também de africanos no tráfico; - à ocupação colonial na perspectiva dos africanos; - às lutas pela independência política dos países africanos; - às ações em prol da união africana em nossos dias, bem como o papel da União Africana, para tanto; - às relações entre as culturas e as histórias dos povos do continente africano e os da diáspora; - à formação compulsória da diáspora, vida e existência cultural e histórica dos africanos e seus descendentes fora da África; - à diversidade 
A HISTÓRIA AFRICANA NAS ESCOLAS BRASILEIRAS...

da diáspora, hoje, nas Américas, Caribe, Europa, Ásia; - aos acordos políticos, econômicos, educacionais e culturais entre África, Brasil e outros países da diáspora. ${ }^{35}$

Apesar de essa iniciativa possuir ingredientes elogiáveis, percebe-se também uma clara tendência em vincular o estudo da história africana ao estudo da história dos afro-descendentes. Os três tópicos que antecedem ao último, acima apontados, revelam tal perspectiva. A princípio não somos contra esse tipo de aproximação relacional, mas defendemos a idéia que ela deveria aparecer em outro tópico, referente, por exemplo, à história Atlântica ou a história da Diáspora, cabendo o estudo da história da África, uma abordagem acerca da trajetória histórica do continente, em seu próprio eixo espaço-temporal. É claro que esse recorte também incluiria as múltiplas relações mantidas com outros conjuntos civilizatórios ou sociedades, mas sempre com o foco principal na África. Além disso, por mais extensa que seja a lista, nos parece óbvio que seria impossível tratar todos os temas ou sugestões de abordagens sobre a história africana. Talvez, nesse caso, os autores pudessem ter optado por sugerir recortes temáticos, temporais e espaciais mais abrangentes, citando especificamente algumas referências apenas como exemplos possíveis.

Já os conteúdos voltados para o estudo da cultura africana receberam um tópico próprio para sua abordagem - como se história e cultura fossem forças antagônicas e não relacionáveis em um mesmo título. Na realidade são assuntos indissociáveis, seja pela sua clara perspectiva temporal ou pela sua natureza temática. Neste caso, parece-nos que as indicações de assuntos se caracterizam pela tendência de deixar escapar o foco do continente africano para colocá-lo sobre os afro-descendentes. Apesar disso devemos reconhecer que essas indicações representam um importante avanço para uma adequada abordagem escolar da história africana.

O ensino de Cultura Africana abrangerá: - as contribuições do Egito para a ciência e filosofia ocidentais; - as universidades 
africanas Timbuktu, Gao, Djene que floresciam no século XVI; as tecnologias de agricultura, de beneficiamento de cultivos, de mineração e de edificações trazidas pelos escravizados, bem como a produção científica, artística (artes plásticas, literatura, música, dança, teatro), política, na atualidade. ${ }^{36}$

Para além das referências aos conteúdos a serem apresentados aos alunos, as Diretrizes sinalizam ainda para a necessidade de inclusão, nos cursos de formação de professores e profissionais da educação de "materiais e de textos didáticos, na perspectiva (...) de estimular o "ensino e aprendizagem da História e Cultura dos Afro-brasileiros e dos Africanos". 37 A mesma indicação é feita a outros cursos superiores, mesmo que não relacionados à formação de docentes ou ligados às áreas das Ciências Humanas, demonstrando a preocupação em ampliar, ao máximo, a abordagem da questão pelos bancos escolares e universitários brasileiros.

Inclusão, respeitada a autonomia dos estabelecimentos do Ensino Superior, nos conteúdos de disciplinas e em atividades curriculares dos cursos que ministra, de Educação das Relações Étnico-Raciais, de conhecimentos de matriz africana e/ou que dizem respeito à população negra. Por exemplo: em Medicina, entre outras questões, estudo da anemia falciforme, da problemática da pressão alta; em Matemática, contribuições de raiz africana, identificadas e descritas pela Etno-Matemática; em Filosofia, estudo da filosofia tradicional africana e de contribuições de filósofos africanos e afrodescendentes da atualidade. ${ }^{38}$

Se em uma visão panorâmica, os textos legais aqui revisitados, sinalizam com maior ou menor intensidades para a necessidade de se abordar a história e as culturas africanas nas escolas brasileiras, é certo também que ainda existe uma distância oceânica a ser vencida entre o que está prescrito daquilo que de fato pode ser encontrado em grande parte de nossas escolas. Vejamos como os especialistas brasileiros na história daquele continente se ocuparam da questão. 
A HISTÓRIA AFRICANA NAS ESCOLAS BRASILEIRAS...

\section{As vozes dos especialistas sobre o ensino da História da África}

A historiografia ${ }^{39}$ voltada para o ensino da história africana tem vivenciado no espaço atlântico um enfoque de crescente interesse, paralelo àquele ocorrido nos estudos históricos realizados sobre a África, porém em uma escala bem menor. Para além dos textos e reflexões realizadas pelo viés do historiador, outros especialistas - na maioria das vezes ligados à Antropologia e à Literatura - também têm se dedicado a lançar questões e formular propostas acerca do tema. No entanto, se comparadas às demais áreas de investigação histórica, os estudos sobre a abordagem escolar das trajetórias temporais das sociedades africanas ainda é incipiente, apesar das importantes contribuições localizadas no Brasil.

Dessa forma, procuraremos aqui, dar notícias de alguns dos trabalhos elaborados em busca de um entendimento mais ampliado sobre o assunto, já que os apontamentos e as incursões investigativas sobre a presença da história da África em nossas escolas receberam poucos adeptos nessa margem do Atlântico. Nossa intenção, portanto, é estabelecer um diálogo em torno de três temas: a. O panorama vivenciado nas últimas duas décadas ao que se refere a abordagem da história da África nas escolas brasileiras; b. As justificavas defendidas pelos especialistas que motivariam o ensino da temática; c. As

perspectivas, sugestões e recortes apresentados para contemplar de forma satisfatória ou adequada o assunto nas salas de aula brasileiras.

Apesar da publicação da lei 10639/03, ou talvez, motivado por ela, encontramos um quadro ainda em mudança em relação às preocupações e reflexões acadêmicas acerca do ensino da história africana. Ressalvando-se algumas exceções, foram apenas nos últimos quatro anos, às vezes um pouco antes, que nossos especialistas em estudos africanos começaram a tecer considerações mais específicas acerca do lugar da África no sistema educacional brasileiro. Isso não significa que, em um tempo mais afastado, como ao longo da década de 1990, ou mesmo antes, iniciativas não tenham sido intentadas. Vamos 
encontrar, naqueles anos, em alguns espaços universitários, como na Universidade de Brasília, na Universidade de São Paulo, na Universidade Federal da Bahia e na Universidade Cândido Mendes, a oferta de cursos de Extensão e de Especialização com enfoques destinados à África, voltados justamente para professores das redes pública e privada de ensino, no sentido de qualificá-los minimamente para a abordagem do assunto em suas salas de aulas. Porém, eram esforços isolados, que não espelhavam uma política pública ou de uma ação em conjunto.

Tais iniciativas também não resultaram diretamente na produção de uma historiografia sobre o tema. Sendo assim, alguns pesquisadores, em um exercício de conversão de seus estudos, do acúmulo de conhecimentos e das leituras sobre a história da África têm se esforçado para produzir textos mais sistematizados acerca da questão. Neste caso, vamos encontrar de 2003 para cá algumas obras em formato de coletânea, que justamente se propõem a tratar a questão por vários ângulos e perspectivas, além é claro de alguns artigos publicados em revistas especializadas ou da área de História. Atentemos para algumas das considerações realizadas nesses espaços.

Em torno do primeiro elemento eleito para sistematização das reflexões formuladas pelos especialistas, ou seja, o panorama de como o tema foi retratado nas escolas brasileiras nos últimos anos, vamos encontrar conclusões bastante parecidas que apontam para a existência de uma grande lacuna ou para um período de intensos esquecimentos.

De acordo com a historiadora Selma Pantoja, a relação do continente africano com a educação brasileira foi, durante as últimas décadas, caracterizada pela "desinformação completa" e pelo silêncio perturbador.

O silêncio diz muita coisa: historicamente o continente é visto invariavelmente como o fornecedor de escravos. Hoje em dia urge suprir as muitas falhas referentes ao ensino da dinâmica Histórica da África e de diferentes abordagens da cultura negroafricana além das relações daquele continente com as Américas e não só com o Brasil (...). A idéia de uma África a-histórica 
A HISTÓRIA AFRICANA NAS ESCOLAS BRASILEIRAS...

provocada pela colonização européia, infelizmente, ainda é predominante no nosso país. ${ }^{40}$

O historiador Valdemir Zamparoni também destaca os silêncios acerca da África nos bancos escolares brasileiros, frutos de uma percepção eurocêntrica e parcial da trajetória histórica da humanidade.

Quem olha para os currículos escolares, do primeiro grau à universidade - salvo raras exceções - não vê a presença negra, senão restrita a algumas lamúrias nas poucas páginas dedicadas à escravatura. Nossos currículos, no entanto, são eurocêntricos. ${ }^{41}$

Ainda na direção dos "esquecimentos" e das ausências africanas nos currículos escolares e no ensino da História, a historiadora Mônica Lima, nos lembra do próprio alerta realizado pela promulgação da lei 10639/03. Ora, por que a obrigatoriedade legal para inclusão de conteúdos da história da África nos currículos utilizados no Brasil? A resposta parece ser óbvia: o tema seria importante e teria sido, por muitos anos, negligenciado por programas, livros didáticos, professores e estudantes. Segundo Lima, as origens desse descaso encontrariam uma longa tradição, identificadas, por exemplo, pelas posturas de alguns intelectuais brasileiros no decorrer dos dois últimos séculos. ${ }^{42}$

Em contrapartida, a renovação dos olhares lançados sobre o continente africano, por parte de um crescente grupo de pesquisadores que tem se dedicado a investigar e refletir sobre a África de dentro das trincheiras acadêmicas brasileiras, não repercutiu como deveria nos corredores universitários, e, conseqüentemente, em nossas escolas.

Os estudos recentes mudam essa visão, mas é preciso saber levá-la às salas de aula. Antes, ainda, é preciso que a universidade deixe, ela também, de ignorar o tema. Que história será esta, se a maioria dos professores em atividade não a conhece $?^{43}$ 
Essa idéia aparece reforçada pelos comentários da historiadora Hebe Maria Mattos que destaca, justamente, o distanciamento percebido entre as prescrições programáticas expostas nos PCNs e a atividade docente em sala de aula. A crítica direciona-se para a pouca atenção concedida ao tema pelos pesquisadores universitários e para a suposta ausência da história africana nos materiais escolares.

Ainda mais grave, há alguns conteúdos fundamentais propostos nos novos PCNs - especialmente a ênfase na história da África que, infelizmente, ainda engatinham como área de discussão e pesquisa nas nossas universidades, impondo-se como limite ainda maior ao esforço pedagógico que pode ser feito para uma abordagem que rompa com o europocentrismo que ainda estrutura os programas de ensino das escolas. Esses limites e distorções refletem-se, necessariamente, na própria produção dos melhores livros didáticos. ${ }^{44}$

Mesmo discordando de sua sentença acerca do estágio dos estudos africanos em nossas universidades - se eles não atingiram um patamar quantitativo esperado, não podemos ignorar que competente grupo de investigadores tem dedicado à temática um tratamento criterioso, relevante e esclarecedor em diversos sentidos - a outra parte de seu argumento tem um embasamento difícil de ser desconstruído, apesar também de encontrarmos algumas exceções. Em artigo recente também apontávamos para um quadro similar ao acima descrito, com ênfase nas dificuldades de transposição didática da nova e consistente onda de estudos africanistas que tem varrido, ainda com um impacto de pequenas dimensões, apesar dos excelentes trabalhos, as universidades brasileiras.

Em uma abordagem panorâmica, percebemos, porém, que a aproximação entre a nova massa de conhecimentos explicativos e críticos sobre a África e os conteúdos trabalhados nas aulas de história, em escolas brasileiras e portuguesas, ainda permanece marcada por tensões inquietantes, prolongados silêncios e um descaso que, apenas aos poucos, está sendo superado. Ou seja, 
A HISTÓRIA AFRICANA NAS ESCOLAS BRASILEIRAS...

parece não haver uma conexão sólida entre aquilo que se pesquisa em centros de estudos e universidades, a própria formação dos professores e os conteúdos apresentados em livros escolares. ${ }^{45}$

Já acerca do segundo tópico elencado para nossas reflexões, um dos motivos mais plausíveis e acertados de expor o assunto seria, de acordo com alguns especialistas, situá-lo numa condição de igualdade de relação com os outros conjuntos históricos, comumente estudados pelos pesquisadores e enfocados nas aulas de história. Ou seja, "estudar a História da África faz parte do conhecimento geral", como argumenta Selma Pantoja, é "como estudar a História da América, da Europa e da Ásia". Soma-se a tal perspectiva a necessidade de corrigir percepções distorcidas ou desequilibradas sobre o continente africano, como confundir o "estudo da história da África nos períodos recuados" com o "estudo da escravidão". ${ }^{46}$

Ainda no campo dos conteúdos a serem trabalhados ou (re)trabalhados nas salas de aula, Mônica Lima chama a atenção para outra questão essencial: a redefinição do lugar ocupado pela África e pelos africanos nos estudos históricos. Se antes, os africanos eram associados às imagens da escravidão, dos "dominados" e explorados, e a África era pensada como o "cenário da Expansão Colonial", a abordagem escolar adequada da história africana possibilitaria a construção de uma imagem positiva e renovada sobre os diversos contextos e circuitos históricos africanos. ${ }^{47} \mathrm{~A}$ mesma problemática é apontada por Hebe Mattos, que destaca a preocupação com as "assimetrias entre o conhecimento das sociedades européias, ameríndias e africanas". 48

Os equívocos da abordagem do tráfico e da escravidão, de fato, aparecem entre alguns dos pontos mais questionados pelos historiadores, até por que, estes, são uns dos poucos temas recorrentemente tratados em sala de aula e nos quais os africanos e a África são citados. Selma Pantoja, por exemplo, alerta para as imprecisões e incorreções aí localizadas. 
O tráfico negreiro ainda é tratado de forma a ceder ao europeu o papel de único agente no comércio. (...) O mundo africano naquele momento é passado como um ambiente de constantes guerras "tribais", tendo-se aproveitado disto os europeus. Mais grave ainda é passar a noção de que toda a população estava dispersa na floresta e portugueses, holandeses, ingleses, etc. os caçavam jogando-os em navios negreiros. ${ }^{49}$

Neste caso, e em concordância com os argumentos da historiadora Mônica Lima, seria fundamental retirar o continente africano do espaço reflexivo marcado pelas generalizações, estereótipos e vitimizações, e valorizar a perspectiva da África como um universo histórico-cultural diverso e complexo. ${ }^{50}$

O historiador e antropólogo Carlos Wedderbun também defende a idéia de que para combater uma tradição multissecular de leituras preconceituosas e, de forma mais recente, marcadamente eurocêntricas, seria preciso destacar determinados aspectos da trajetória histórica africana, com ênfase em alguns pontos fundamentais, como: o estudo das singularidades do continente - "berço da humanidade, diversidade geográfica e populacional, local do desenvolvimento das primeiras civilizações" - e de seus vários recortes históricotemático-temporais. ${ }^{51}$

Outro aspecto lembrado pelos especialistas relaciona-se à questão da construção da identidade nacional brasileira, ou melhor, do lugar da africanidade nessa identidade e no combate ao racismo. Para Lima, seria natural que as crianças tivessem dificuldades em se identificar com uma história construída por elementos e imagens carregadas de poucos valores e muitos estereótipos. $^{52}$

Em texto elaborado em 2005, para compor material didático utilizado em curso de formação de professores do Ensino Fundamental e Ensino Médio sobre a história africana, defendíamos, por fim, outra justificativa acerca da relevância da aplicação escolar dos estudos africanos. 
A HISTÓRIA AFRICANA NAS ESCOLAS BRASILEIRAS...

E, por fim, existe o caráter formativo/intelectual do assunto, o motivo de maior importância entre os apresentados. A África possui tantas escolas de pensadores, de artistas, de intelectuais, e contribuições para o entendimento e construção do patrimônio histórico/cultural da humanidade que é inadmissível simplesmente não estudá-la..$^{53}$

Por fim, o último elemento a inventariar, refere-se às perspectivas e propostas para incentivar ou estruturar o ensino da história da África nas escolas brasileiras. Neste caso, os pesquisadores que se debruçaram sobre o tema, buscaram construir um quadro indicativo envolvendo atividades, conteúdos e metodologias que poderia ser articulado ao tratamento do assunto nas salas de aula.

Para Carlos Wedderburn, o trabalho com os estudos africanos só tornar-se-ia possível ou viável a partir de uma "abordagem transversal, transdisciplinar e de longa duração", marcada por um enfoque diacrônico das trajetórias históricas das sociedades africanas e de suas relações com o mundo exterior ${ }^{54}$ Apesar de concordar com a idéia apresentada, acreditamos que o encaminhamento sugerido por Wedderburn, indique uma trilha caracterizada por uma opção teórico-analítica com limites já bastante conhecidos e debatidos em períodos anteriores.

No que concerne à construção de uma metodologia eficiente para o ensino da história africana, Wedderburn, aponta, de forma bastante lúcida, para a necessidade de se cruzarem, numa síntese, as perspectivas metodológicas de alguns dos principais historiadores africanos, como Joseph Ki-Zerbo, Cheik Anta Diop, Elikia M'Bokolo, Théophile Obenga, entre outros. Apesar das divergências apresentadas por esses autores, tornarse-ia possível, a partir deles, o estabelecimento ou definição dos espaços-civilizatórios e períodos a serem estudados. Um dos pontos mais instigantes e, ao mesmo tempo, mais complicados na proposta de Wedeerburn é a formulação bastante detalhada dos recortes históricos elencados que, separadamente, indicam algumas trilhas a serem seguidas: são quinze espaços 
civilizatórios-políticos abordados em dez recortes cronológicos. Talvez, o maior problema da proposta seja a dificuldade em se construir uma visão de conjunto da história do continente. Não devemos esquecer que preservar as singularidades de suas regiões não deve ser ação encarada como um elemento que impeça uma possível leitura panorâmica sobre suas realidades. ${ }^{55}$ No mais, Wedderburn, acredita que a melhor esquematização para se trabalhar a história africana nos ensinos fundamental e médio seria a seguinte:

Há critérios divergentes sobre como direcionar metodologicamente os estudos sobre a África, dependendo dos diferentes níveis de ensino. Para muitos é necessário manter um enfoque linear-factual (...) para níveis correspondentes ao ensino fundamental. (...) O ensino médio é a porta de entrada para o mundo acadêmico, portanto se espera que nesse nível a história africana já seja abordada de forma complexa. ${ }^{56}$

Neste caso, outra perspectiva possível é apontada por Selma Pantoja, que defende a tendência de se estudar a história da África de "maneira global e não parcelar". O risco de estudar a África "em porções" seria o de preservar um conjunto de idéias e imagens que projetam um continente longínquo. ${ }^{57}$ Já sobre os conteúdos que poderiam ser abordados, a historiadora aponta, entre outros temas, para os seguintes:

(...) enunciar as origens da humanidade, discutir a questão da "anterioridade africana" e as relações ativas dos africanos com os oceanos e outras partes do mundo. A partir daí, pode-se chegar a uma abordagem de uma História da África por ela mesma. ${ }^{58}$

Para além dessas indicações, Pantoja indica para outro elemento central nas transformações esperadas acerca da abordagem escolar da história africana que seria a necessidade de ampliar a "formação de professores e pesquisadores africanistas" ${ }^{59}$ Já a questão da paridade entre os estudos da história européia e da história africana também é advogada por 
A HISTÓRIA AFRICANA NAS ESCOLAS BRASILEIRAS...

Hebe Maria Mattos, assim como o cuidado com a formação dos professores ${ }^{60}$.

Por fim, Mônica Lima, aponta para um conjunto mais detalhado de procedimentos e temas que poderiam propiciar um tratamento adequado à questão. A preocupação com a formação dos professores, como alertamos acima, também freqüenta suas sugestões, em um sentido mais de reivindicação dos segmentos envolvidos com a educação do que de livre iniciativa do Estado e instituições competentes para tal. Neste caso, sua indicação gira em torno da necessidade de estudantes de graduação exigirem a "inclusão efetiva desses assuntos nos currículos de suas faculdades" e de professores na ativa solicitarem cursos de qualificação sobre a temática. Em todos os casos, a organização de grupos de estudo e pesquisa poderia também minimizar as defasagens encontradas em suas formações profissionais. ${ }^{61}$

$\mathrm{E}$, independentemente da qualificação em estudos africanos, já seria possível aos docentes, trilhar alguns caminhos considerados positivos sobre o tema. Para a primeira parte do ensino fundamental, Lima, sugere o trabalho com "lendas, contos, cantigas, brincadeiras", já para suas séries finais, a indicação seria o estudo do "processo de humanização", "o esplendor do Antigo Egito" e dos "grandes reinos africanos". Para o ensino médio, as idéias a serem tratadas girariam em torno do racismo, do processo de ocupação colonial e da África contemporânea. ${ }^{62}$

\section{Considerações Finais}

Estabelecido esse breve diálogo entre as prescrições legais acerca do ensino da história africana e os apontamentos dos especialistas sobre a temática, podemos sintetizar algumas tendências percebidas. Em primeiro lugar visualizamos a existência de um panorama que aponta para possíveis mudanças sobre a questão nos próximos anos. O esforço de algumas Universidades, de pesquisadores e de órgãos governamentais em ofertar cursos de Extensão, Formação ou 
Especialização indica tal caminho. O interesse despertado em torno da questão e o espaço ocupado pelas mesmas em meio aos debates educacionais também são bons indícios. A preocupação dos textos oficiais em determinar algumas balizas de conteúdos e de significados para o estudo de temas envolvendo a história africana encerra esse olhar otimista sobre o assunto.

No entanto, ao mesmo tempo em que a legislação específica sobre a inclusão da história da África nas escolas brasileiras pode ser considerada um avanço no campo da prescrição, o debate com nossos africanistas sinaliza para a evidente constatação de que mesmo com as iniciativas vivenciadas nos últimos anos, muito ainda esta por ser feito. A formação de especialistas na área, a publicação de mais textos e a realização de mais investigações sobre o tema, a necessidade de melhor definir o que deve e pode ser trabalhado em sala de aula e, fundamentalmente, desconstruir um grande número de estereótipos e falsas imagens sobre a África e as sociedades africanas, são algumas de suas indicações. Sendo assim, a perspectiva de mudanças só poderá se concretizar com a contínua e crescente atenção dedicada ao tema, seja nos programas de pós-graduação, nas associações de docentes e pesquisadores, nas ações governamentais e nos bancos escolares. Talvez, assim, daqui a alguns anos as distâncias entre a África e nossos estudantes não seja mais oceânica.

OLIVA, Anderson Ribeiro. The African history in schools Brazilian. Between the legislation and lived, the eyes of the educational law specialists (1995-2006). História, v.28, n.2, p.143172, 2009.

Abstract: This article has as main intention to establish a dialogue between the Brazilian legislation on the teaching of African history and the readings and opinions expressed by some africanists on the subject. Therefore, we sought in the first part of the text mapping the presence of African studies in the National Curricular Parameters, in Law 10639/03 and the guidelines formulated to allow its implementation. In the second part of our 
A HISTÓRIA AFRICANA NAS ESCOLAS BRASILEIRAS...

exercise was to the prospect of watching how historians, anthropologists and other experts examined the approach of African history in our school banks in the last ten years. The outcome of the dialogue shows that, despite indications found in the Brazilian educational legislation, a long gap when it presents itself to be treated in classrooms involves African issues.

Keywords: Teaching of African history; Law 10639/03; History of Africa.

\section{NOTAS}

1 Este trabalho é um dos resultados obtidos pela investigação desenvolvida no doutorado junto ao Programa de Pós-Graduação em História da UnB, que recebeu apoio financeiro da Coordenação de Aperfeiçoamento de Pessoal de Nível Superior (Capes).

${ }^{2}$ Ver os seguintes livros didáticos: MACEDO, José Rivair; OLIVEIRA, Mariley W. Uma história em construção, vol. 3. São Paulo: Editora do Brasil, 1999; MARANHÃO, Ricardo; ANTUNES, Maria Fernanda. Trabalho e Civilização: uma história global, 2. São Paulo: Moderna, 1999; e SCHMIDT, Mario. Nova História Crítica, $6^{a}$ série. São Paulo: Nova Geração, 2002.

${ }^{3}$ De acordo com o pesquisador Sales Augusto dos Santos, a primeira lei municipal que explicitava a obrigatoriedade do ensino da história africana nas escolas foi a Lei Orgânica do Município de Belo Horizonte, de 21 de março de 1990. No seu artigo 182, parágrafo VI ela indica "a inclusão de conteúdo programático sobre a história da África (...)". Já a Constituição do Estado da Bahia sinaliza apenas para "a adequação dos programas de ensino (...) à realidade histórica afro-brasileira" (SANTOS, Sales Augusto. A lei no 10.639 como fruto da luta anti-racista do movimento negro. In: Educação Anti-racista: caminhos abertos pela Lei Federal 10.639/03. Brasília: MEC; Secad, 2005, pp. 21-37). De acordo com Petronilha Beatriz Gonçalves e Silva, membro do Conselho Nacional de Educação, a legislação precedente em relação à obrigatoriedade do estudo da história e cultura afro-brasileira é mais extensa, apesar também de não apresentar, na esmagadora maioria dos casos, um espaço reservado ao estudo da história africana, propriamente dita (ver CONSELHO NACIONAL DE EDUCAÇÃO. 
Diretrizes Curriculares Nacionais para a Educação das Relações ÉtnicoRaciais e para o Ensino de História e Cultura Afro-Brasileira e Africana. Parecer $\mathrm{n}^{\circ} 003$ de 2004, de 10 de março de 2004, p. 1).

4 SECRETARIA DE EDUCAÇÃO FUNDAMENTAL. Parâmetros Curriculares Nacionais. Terceiro e quarto ciclos do ensino Fundamental: introdução aos parâmetros curriculares nacionais. Brasília: MEC/SEF, 1998, p. 55.

${ }^{5}$ LEI DE DIRETRIZES E BASES DA EDUCAÇÃO NACIONAL (LDB), lei $\mathrm{n}^{\circ}$ 9394, de 20 de dezembro de 1996, art. 25 § $4^{\circ}$.

6 SECRETARIA DE EDUCAÇÃO FUNDAMENTAL. Parâmetros Curriculares Nacionais. Terceiro e quarto ciclos do ensino Fundamental: introdução aos parâmetros curriculares nacionais, p. 60.

7 SECRETARIA DE EDUCAÇÃO FUNDAMENTAL. Parâmetros Curriculares Nacionais: História. Brasília: MEC/SEF, 1998, p. 43.

${ }^{8}$ Idem, pp. 35-36.

${ }^{9}$ Ver LDB, art. 26.

10 SECRETARIA DE EDUCAÇÃO FUNDAMENTAL. Parâmetros Curriculares Nacionais: História, p. 57.

11 SECRETARIA DE EDUCAÇÃO FUNDAMENTAL. Parâmetros curriculares nacionais. Pluralidade Cultural. Brasília: MEC/SEF, 1998, pp. 130-131.

${ }^{12}$ Idem, p. 125.

${ }^{13}$ Usamos aqui a organização do sistema educacional brasileiro vigente até 2007.

14 SECRETARIA DE EDUCAÇÃO FUNDAMENTAL. Parâmetros Curriculares Nacionais: História, p. 55.

${ }^{15}$ Idem, p. 59.

${ }^{16}$ Ver M' BOKOLO, Elikia. África Negra História e Civilizações. Até ao século XVIII. Lisboa: Vulgata, 2003, pp. 20-28; DIOP, Cheick Anta. Antériorité des civilisations nègres mythe ou vérité histórique? Paris: Présence Africaine, 1967 e DIOP, Cheick Anta. A origem dos antigos egípcios. In: MOKHTAR, G. História Geral da África, vol. II: A África Antiga. São Paulo: Ática; Unesco, 1983, pp. 39-70.

17 SECRETARIA DE EDUCAÇÃO FUNDAMENTAL. Parâmetros Curriculares Nacionais: História, p. 55.

${ }^{18}$ Idem, p. 59.

${ }^{19}$ Idem, p. 57.

${ }^{20}$ Idem, pp. 60-61.

${ }^{21}$ Idem, p. 60. 


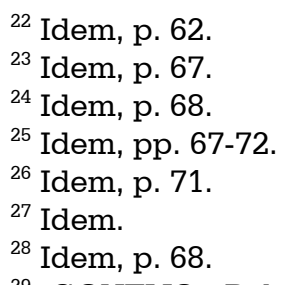

29 GONTIJO, Rebeca. Identidade Nacional e Ensino de História: a diversidade como "patrimônio sociocultural. In: ABREU, Martha; SOIHET, Rachel. Ensino de História: conceitos, temáticas e metodologia. Rio de Janeiro: Casa da Palavra; FAPERJ, 2003, p. 65.

${ }^{30}$ Ver: ABREU, Martha; SOIHET, Rachel. Op. cit.. Sobre uma reflexão mais apurada acerca dos debates e impactos das teses do Multiculturalismo ver SOUZA, Jessé (org.). Multiculturalismo e Racismo: uma comparação Brasil - Estados Unidos. Brasília: Paralelo 15, 1997.

${ }^{31}$ LOPES, Carlos. A Pirâmide Invertida - historiografia africana feita por africanos. In Actas do Colóquio Construção e Ensino da História da África. Lisboa: Linopazas, 1995, pp. 21-29.

${ }^{32}$ Uma esclarecedora abordagem sobre o tema pode ser encontrada no seguinte artigo: FARIAS, Paulo F. de Moraes. Afrocentrismo: entre uma contra-narrativa Histórica universalista e o Relativismo Cultural. Revista Afro-Ásia, n² 29-30, 2003, pp. 317-343.

33 MINISTÉRIO DA EDUCAÇÃO; SECRETARIA ESPECIAL DE POLÍTICAS DE PROMOÇÃO DA IGUALDADE RACIAL. Diretrizes Curriculares Nacionais para a Educação das Relações Étnico-Raciais e para o Ensino de História e Cultura Afro-Brasileira e Africana. Brasília: MEC, 2004, p. 17.

${ }^{34}$ Idem, p.18 e p.21.

${ }^{35}$ Idem, pp. 21-22.

36 MINISTÉRIO DA EDUCAÇÃO; SECRETARIA ESPECIAL DE POLÍTICAS DE PROMOÇÃO DA IGUALDADE RACIAL. Op. cit., p. 22.

${ }^{37}$ Idem, p. 23.

${ }^{38}$ Idem, p. 24.

${ }^{39} \mathrm{Na}$ realidade não é uma produção sistematizada, com grupos ou "escolas" articuladas em torno do tema. São reflexões, apontamentos, críticas e sugestões da historiografia africanista acerca da questão.

${ }^{40}$ PANTOJA, Selma. A África imaginada e a África real. In: PANTOJA, Selma; ROCHA, Maria José (orgs.). Rompendo Silêncios: História da 
África nos currículos da educação básica. Brasília: DP Comunicações, 2004, pp. 22-23.

${ }^{41}$ ZAMPARONI, Valdemir. A situação atual dos estudos africanos no Brasil. In: Actas do Colóquio Construção e Ensino da História da África. Op. cit., pp. 515-515.

${ }^{42}$ LIMA, Mônica. A África na Sala de Aula. Nossa História, ano 1, $\mathrm{n}^{\circ} 4$, fevereiro de 2004, p. 84.

${ }^{43}$ Idem, p. 85.

44 MATTOS, Hebe Maria. O Ensino de História e a luta contra a discriminação racial no Brasil. In: ABREU, Martha; SOIHET, Rachel. Op. cit., p. 131.

${ }^{45}$ OLIVA, Anderson Ribeiro. O ensino da História africana. A presença da África nos manuais escolares brasileiros e portugueses. In: PANTOJA, Selma (org.). Identidades, Memórias e História em Terras Africanas. Brasília: LGE; Luanda: Nzila, 2006, p. 139.

${ }^{46}$ PANTOJA, Selma. A África imaginada e a África real. In: PANTOJA, Selma; ROCHA, Maria José (orgs.). Op. cit., p. 22.

${ }^{47}$ LIMA, Mônica. A África na Sala de Aula. Op. cit., p. 84 e p. 85.

${ }^{48}$ MATTOS, Hebe Maria. Op. cit., p. 133.

${ }^{49}$ PANTOJA, Selma. Op. cit., p. 22.

${ }^{50}$ LIMA, Mônica. Op. cit., p. 85.

${ }^{51}$ WEDDERBURN, Carlos Moore. Novas bases para o Ensino da História da África no Brasil. In: Educação Anti-racista: caminhos abertos pela Lei Federal 10.639/0. Brasília: MEC-SECAD, 2005, pp. 134-142.

${ }^{52}$ LIMA, Mônica. Op. cit., p. 85.

${ }^{53}$ OLIVA, Anderson Ribeiro. A História Africana nas Escolas: entre abordagens e perspectivas. In: Educação Africanidades Brasil. Brasília: MEC- SECAD/UnB-CEAD, 2005, p. 88.

${ }^{54}$ WEDDERBURN, Carlos Moore. Op. cit., pp. 141-142.

${ }^{55}$ Idem, pp. 141-152.

${ }^{56}$ Idem, p. 143.

${ }^{57}$ PANTOJA, Selma. Op. cit., p. 22.

${ }^{58}$ Idem.

${ }^{59}$ Idem, p. 23.

${ }^{60}$ MATTOS, Hebe Maria. Op. cit., p. 134.

${ }^{61}$ LIMA, Mônica. Op. cit., p. 85-86.

${ }^{62}$ Idem, p. 86.

Artigo recebido em 03/2009. Aprovado em 07/2009. 